\title{
The "Bedi-IMA Buttress": Reinforcement of the Bronchial Stump with a Pedicled Internal Mammary Artery Buttress in Diabetic Patients after Lung Resection
}

\author{
Harinder Singh Bedi*, Kamal Negi \\ Christian Medical College \& Hopital, Ludhiana, India \\ Email: ${ }^{*}$ drhsbedicmc@gmail.com
}

Received 3 October 2014; revised 3 November 2014; accepted 28 November 2014

Copyright (C) 2014 by authors and Scientific Research Publishing Inc.

This work is licensed under the Creative Commons Attribution International License (CC BY).

http://creativecommons.org/licenses/by/4.0/

(c) (i) Open Access

\begin{abstract}
Objective: The development of a bronchopleural fistula is a devastating complication after lung resection. We describe a new method of buttressing the closure of the stump in diabetic patients using a pedicled internal mammary artery buttress flap to avoid a bronchopleural fistula. Methods: An internal mammary pedicled flap was used in 14 diabetic patients of lung resection to cover the bronchial stump. Results: The flap of viable vascularized muscle mass gave an excellent coverage of the bronchial stump. All patients recovered well with no bronchopleural fistula. Conclusions: We recommend this technique as a method of buttressing the bronchial stump in cases of lung resection, as the internal mammary artery is easily available and its use is not associated with any side effects.
\end{abstract}

Keywords

Lung, Lobectomy (Lung), Thoracotomy

\section{Introduction}

The development of a bronchopleural fistula (BPF) after lung resection is a serious complication with a reported incidence of $4 \%$ to $12 \%$ [1]. Extra coverage and re-inforcement of the bronchial stump with surrounding tissue have been used in an attempt to decrease the incidence of BPF [1]-[4]. Different biological materials [1]-[4]

${ }^{*}$ Corresponding author.

How to cite this paper: Bedi, H.S. and Negi, K. (2014) The "Bedi-IMA Buttress": Reinforcement of the Bronchial Stump with a Pedicled Internal Mammary Artery Buttress in Diabetic Patients after Lung Resection. World Journal of Cardiovascular Surgery, 4, 223-226. http://dx.doi.org/10.4236/wjcs.2014.412032 
such as pleura, intercostal muscle pericardial fat pad, diaphragm, azygos vein (in right-sided pneumonectomy), pericardiophrenic pedicles and the patient's own pericardium have been used. Diabetic patients undergoing lung resections are at increased risk for postoperative BPF [1]. This is mainly due to the microangiopathy caused by diabetes, which alters the vascularity and oxygen diffusion capacity at the bronchial stump and thus impairs proper healing. We describe a new technique with the pedicled internal mammary artery (IMA) - the "BediIMA Buttress”- to cover the bronchial stump in diabetic patients after lung resection.

\section{Material and Methods}

14 patients underwent the procedure. The study was approved by the Institute Ethics committee and the patients gave an informed consent to the use of the technique. All patients had insulin dependent diabetes mellitus (IDDM) of over 5 years duration with good control. There were 12 male and 2 female patients. The age range was 45 - 78 years (average 55.6 years).The indication for resection (3 pneumonectomies, 11 lobectomies) was Stage 1 lung cancer in 3, bronchiectasis in 5 and cavity with fungal ball (aspergilloma) and hemoptysis in 6 . None of the cancer patients had preoperative chemotherapy or radiotherapy. A cardiology clearance was taken in all cases and no patient was clinically found to have ischemic heart disease (IHD).

\subsection{Preoperative Assessment}

All patients underwent a standard set of investigations before operation. These included, plain chest roentgenograms, computed tomography (CT) of the chest, fiberoptic bronchoscopy to assess the airway and tumor resectability and spirometry. All patients were assessed by the same medical and surgical teams from our Institute.

\subsection{Surgical Technique}

A standard postero-lateral thoracotomy was performed in all and the lung resection performed. In the patients with lung cancer tumor negativity of resection margins was confirmed by histologic examination of frozen sections. Bronchial stump closure was performed with mechanical staplers (Ethicon Endo surgery, J \& J, Guaynabo, Puerto Rico, USA). The integrity of the closure was tested by filling the lung cavity with warm saline and increasing the ventilatory pressure to $30 \mathrm{~cm} \mathrm{H}_{2} \mathrm{O}$. The stumps were then covered.

\subsection{Coverage of the Bronchial Stump}

The IMA was then harvested using standard techniques [5] with electro-cautery and liga clips. The IMA was identified easily at the back of the sternum. The endothoracic fascia was incised with electrocautery at low setting medially and laterally $2 \mathrm{~cm}$ from the IMA in a tram-track fashion. The IMA along with its veins, fascia, and a generous amount of muscle and fat was separated from the chest wall leaving a bare IMA bed behind. Branches were controlled with small-sized hemostatic clips frequently only by the IMA side. The IMA was dissected up to its bifurcation. The distal end was now divided, good flow confirmed and the cut end controlled with a hemostatic clip. The IMA buttress flap was brought down and sewn over the bronchus in a cap like fashion using interrupted 4 - 0 Prolene sutures (Ethicon, Somerville, NJ) so that the whole bronchial stump was covered. All patients were extubated after surgery in the operation theatre and received standard postoperative care. Primary outcomes of interest looked for were the development of BPF and empyema. All patients were seen in outpatient surgical clinic 1 month after surgery and at 6-month intervals thereafter. Follow-up was a mean $16 \pm 9.2$ months (range 7 to 24 months) Figure 1 .

\section{Results}

The IMA exposure was excellent through the postero-lateral thoracotomy. The harvesting was easy and took an average of 8.8 minutes. The median hospital stay was 8 days (range 5 to 15 days). Perioperative mortality was 0 . No case of BPF occurred during the early or late follow-up period. The new technique did not have any adverse effect on any patient.

\section{Discussion}

The development of a BPF remains one of the most devastating complications that may arise after lung resec- 


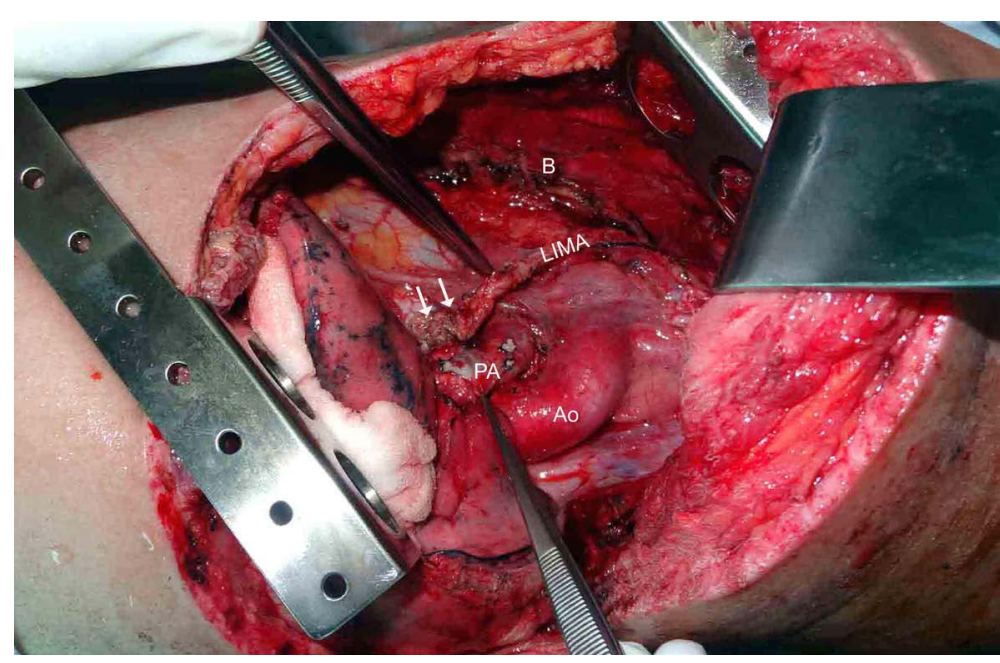

Figure 1. Operative photograph showing the left internal mammary artery (LIMA) flap covering the bronchial stump (double white arrows). B = LIMA bed behind the sternum, Ao = aorta, PA = pulmonary artery.

tions [1]. Protection of the bronchial stump with well-vascularized tissue results in reinforcement of the bronchial stump. Most surgeons agree that it is prudent to buttress bronchi at high risk of developing a BPF with living tissue after lobectomy or pneumonectomy; however, no consensus has been reached on the ideal material to use [1]-[4].

Pedicled pericardial flap or pericardial fat pad, pleura, intercostal muscle, diaphragm, and azygos vein (for right pneumonectomy) have been used as an additional coverage of bronchial stump wound [1]-[4]. The number of techniques is testimony to the fact that no one technique is perfect. The use of the pedicled pericardium or pericardial fat gives a flap which is not vascular. An attempt to gain vascularity by including the pericardiophrenic vessels sacrifices the phrenic nerve. Also there is a need to reconstruct the defect in the pericardium with a Vicryl mesh (to prevent herniation of the heart through the resulting defect)—with the resultant increase in cost, the risk of arrhythmias, intrapericardial infection and the risk of cardiac tamponade due to too tight a reconstruction [4]. The pedicled intercostal muscle flaps have the problem of poor vascularity and there is the potential for developing heterotopic ossification based on the periosteum of the rib which may cause severe problems [6]. Mineo and coworkers [7] have reported excellent results with the use of a diaphragmatic flap to reinforce the bronchial stump after pneumonectomy. Pedicled omental flaps have also been used [8]. Both techniques [7] [8] have the disadvantage of extending the thoracic operation into the abdomen. A major complication of diaphragm flaps is visceral herniation that has to be prevented by using Mersilene mesh to close the diaphragmatic defect. All of these techniques lead to a longer surgical duration and, moreover, weakening of the chest wall or diaphragmatic muscle which can cause respiratory insufficiency during the postoperative course.

The use of a pedicled IMA has the advantage of its own blood supply and a good thickness of well vascularized muscle tissue. It creates a mechanical barrier between the bronchial stump and the thoracic cavity. It is easy and quick to harvest as it is available in the local operating field, causes minimal extra operative trauma and does not require any reconstruction. Harvesting requires no special equipment and can be performed by the general thoracic surgeon. In addition, its length and mobility allows it to reach any bronchi.

Our data support the use of the Bedi-IMA Buttress in diabetic patients undergoing lung resection. Although the results appear encouraging, further studies will probably be needed, along with continued follow-up, to confirm our findings. The major limitation of this study is that it was conducted at a single institution by a single surgeon (HSB) on a very small number of patients with no controls. There is also the theoretical problem in the loss of the IMA in case a coronary artery bypass grafting (CABG) is required later on-although a literature search does not report on any case of a post lung resection patient needing a CABG at a later date. We screen all our cases for the possibility of IHD and would avoid the Bedi-IMA Buttress flap in a patient with CAD.

\section{Conclusion}

The favorable results of the use of a the Bedi-IMA Buttress flap in our study suggest that bronchial stump rein- 
forcement with this technique is a highly effective method for prevention of BPF especially in patients at risk for bronchial healing problems e.g. diabetics.

\section{References}

[1] Sfyridis, P.G., Kapetanakis, E.I., Baltayiannis, N.E., Bolanos, N.V., Anagnostopoulos, D.S., Markogiannakis, A., et al. (2007) Bronchial Stump Buttressing with an Intercostal Muscle Flap in Diabetic Patients. The Annals of Thoracic Surgery, 84, 967-972. http://dx.doi.org/10.1016/j.athoracsur.2007.02.088

[2] Anderson, T.M. and Miller Jr., J.I. (1995) Use of Pleura, Azygos Vein, Pericardium, and Muscle Flaps in Tracheobronchial Surgery. The Annals of Thoracic Surgery, 60, 729-733. http://dx.doi.org/10.1016/0003-4975(95)00500-K

[3] Klepetko, W., Taghavi, S., Pereszlenyi, A., Bîrsan, T., Groetzner, J., Kupilik, N., et al. (1999) Impact of Different Coverage Techniques on Incidence of Postpneumonectomy Stump Fistula. European Journal of Cardiothoracic Surgery, 15, 758-763. http://dx.doi.org/10.1016/S1010-7940(99)00089-5

[4] Taghavi, S., Marta, G.M., Lang, G., Seebacher, G., Winkler, G., Schmid, K., et al. (2005) Bronchial Stump Coverage with a Pedicled Pericardial Flap: An Effective Method for Prevention of Postpneumonectomy Bronchopleural Fistula. The Annals of Thoracic Surgery, 79, 284-288. http://dx.doi.org/10.1016/j.athoracsur.2004.06.108

[5] Calafiore, A.M., Vitolla, G., Iaco, A.L., Fino, C., Giammarco, G.D., Marchesani, F., et al. (1999) Bilateral Internal Mammary Artery Grafting: Midterm Results of Pedicled versus Skeletonized Conduits. The Annals of Thoracic Surgery, 67, 1637-1642. http://dx.doi.org/10.1016/S0003-4975(99)00282-9

[6] Prommegger, R. and Salzer, G.M. (1998) Heterotopic Ossification in Pedicled Intercostal Muscle Flaps Causing Clinical Problems. The Journal of Thoracic and Cardiovascular Surgery, 115, 466-467. http://dx.doi.org/10.1016/S0022-5223(98)70293-4

[7] Mineo, T.C., Ambrogi, V., Pompeo, E., Cristino, B., Natali, G.L. and Casciani, C.U. (1997) Comparison between Intercostal and Diaphragmatic Flap in the Surgical Treatment of Early Bronchopleural Fistula. European Journal of Cardiothoracic Surgery, 12, 675-677.

[8] D’Andrilli, A., Ibrahim, M., Andreetti, C., Ciccone, A.M., Venuta, F. and Rendina, E.A. (2009) Transdiaphragmatic Harvesting of the Omentum Through Thoracotomy for Bronchial Stump Reinforcement. The Annals of Thoracic Surgery, 88, 212-215. http://dx.doi.org/10.1016/j.athoracsur.2009.04.025

$\begin{array}{lcc}\text { Contribution Details (to Be Ticked Marked as Applicable) } \\ \text { Contributor 1 } & \text { Contributor 2 } \\ \text { Concepts } & \text { yes } & - \\ \text { Design } & \text { yes } & - \\ \text { Definition of intellectual content } & \text { yes } & - \\ \text { Literature search } & - & \text { yes } \\ \text { Clinical studies } & \text { yes } & \text { yes } \\ \text { Experimental studies } & - & - \\ \text { Data acquisition } & - & \text { yes } \\ \text { Data analysis } & \text { yes } & - \\ \text { Statistical analysis } & \text { yes } & - \\ \text { Manuscript preparation } & \text { yes } & \text { yes } \\ \text { Manuscript editing } & \text { yes } & - \\ \text { Manuscript review } & \text { yes } & \text { yes } \\ \text { Guarantor } & \text { yes } & -\end{array}$


Scientific Research Publishing (SCIRP) is one of the largest Open Access journal publishers. It is currently publishing more than 200 open access, online, peer-reviewed journals covering a wide range of academic disciplines. SCIRP serves the worldwide academic communities and contributes to the progress and application of science with its publication.

Other selected journals from SCIRP are listed as below. Submit your manuscript to us via either submit@scirp.org or Online Submission Portal.
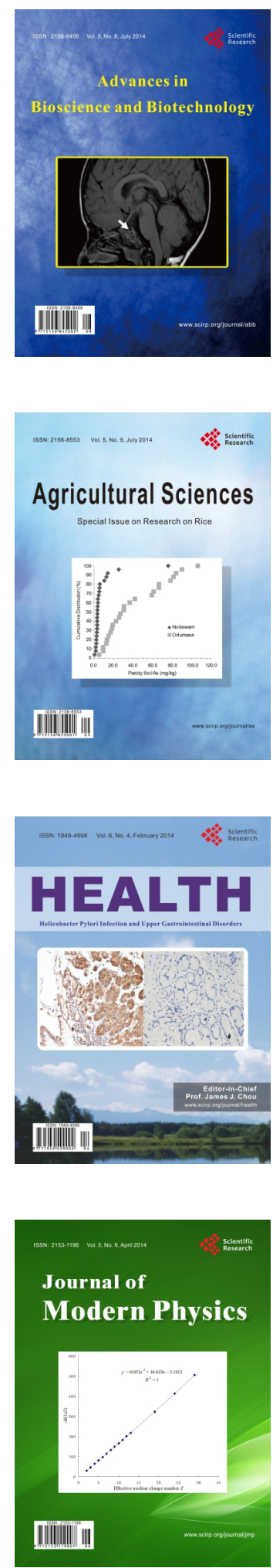
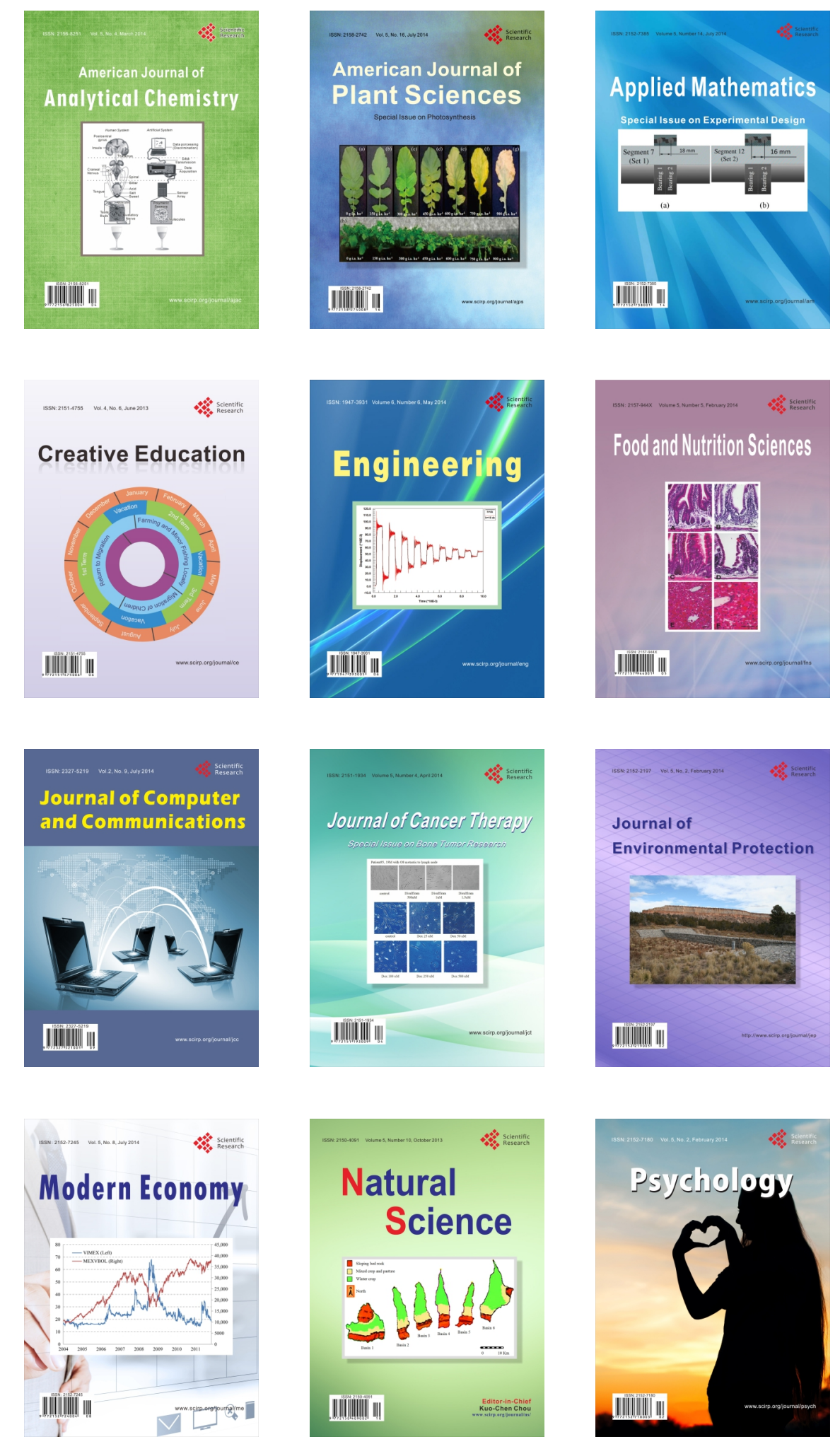